\title{
Thyroid Swellings Undergoing Thyroidectomy in a Tertiary Hospital of Nepal: A Retrospective Study of Distribution and Prevalence of Malignancy
}

\author{
Mudit Gupta, ${ }^{1}$ Rajeev Kumar Mahaseth, ${ }^{2}$ Sajish Khadgi, ${ }^{3}$ \\ Asmita Shrestha, ${ }^{4}$ Neeti Bhat, ${ }^{5}$ Alina Karna ${ }^{6}$ \\ ${ }^{1}$ Department of Oto- Rhinolaryngology, Sri Guru Ram Rai Institute of Medical and Health Sciences, Dehradun, India; \\ ${ }^{2}$ Nepal Army Institute of Health Science Kathmandu, Syanobharyang, Kathmandu, Nepal; \\ ${ }^{3}$ Department of Surgical Oncology, ENT Head \& Neck Unit, B. P. Koirala Memorial Cancer Hospital, Bharatpur, Chitwan, Nepal; \\ ${ }^{4}$ Pokhara Academy of Health Sciences, Ram Ghat, Pokhara, Nepal; \\ ${ }^{5}$ Department of Clinical Physiology, Madan Bhandari Academy of Health Sciences, Hetauda, Nepal. \\ ${ }^{6}$ Department of Pathology and Lab Medicine, Madan Bhandari Academy of Health Sciences, Hetauda, Nepal.
}

\begin{abstract}
Introduction: Thyroid nodules brought to a hospital are checked for cancer. A post-operative histological examination is the gold standard for diagnosing thyroid lesions. Treatment is aided by a prior understanding of the disease's underlying pattern.

Objective: A retrospective study was done to determine the prevalence and distribution of malignancy in suspicious thyroid nodules.

Methods: The study was conducted at Ganesh Man Singh Memorial Academy of ENT- Head and Neck studies from August 2017 to March 2020. All the subjects ( $\mathrm{n}=183$ ) presenting with a thyroid nodule and who had post-operative histopathological evaluation available were recruited in the study. The proportion and percentage of findings of Fine Needle Aspiration Cytology (FNAC) and histopathological evaluation were done. The distribution of histopathological observation was also analyzed in terms of age group and gender.

Results: The mean age of study participants was $40.23 \pm 13.77$ years ( $\mathrm{n}=183$ ). The predominance of women was notable. In about 98 (53.55\%) of the patients who underwent thyroidectomy, a benign lesion was found, but the most common finding was papillary carcinoma (40.98\%). In the age group below 50 years, papillary carcinoma was most common. Among people older than 50, colloid goiter was more common. Follicular and medullary carcinomas were only observed in female participants. Gender did not appear to be associated with malignancy ( $\mathrm{p}=0.99)$. Follicular adenomas were noted to have the youngest mean age.

Conclusions: We observed a high prevalence of malignancy, particularly papillary carcinoma in clinically suspected thyroid nodules of a tertiary hospital in Nepal.

Keywords: Colloid Goiter; malignancy; papillary carcinoma; thyroid cancer; thyroid nodule.
\end{abstract}

\section{INTRODUCTION}

Thyroid malignancy is the most prevalent endocrine malignancy, with an increase in incidence each year. ${ }^{1}$

Correspondence
Dr. Mudit Gupta
Email: muditgupta1858@gmail.com
Citation
Gupta M, Mahaseth RM, Khadgi S, Shrestha A, Bhat N, Karna A.
Thyroid Swellings Undergoing Thyroidectomy in a Tertiary Hospital
of Nepal: A Retrospective Study of Distribution and Prevalence of
Malignancy. Nepal J Health Sci. 2021 Jul-Dec; 1(2): 27-33.

Occasionally, thyroid malignancy may present itself as a thyroid nodule. Environment and genetics play a significant role in the development of thyroid cancer. Mainly, insufficient iodine intake is associated with an increase in the risk of thyroid malignancy. ${ }^{2,3}$ When a subject presents with a thyroid nodule, we perform a thorough medical evaluation because of its malignancy potential, compressive signs, and aesthetic symptoms. Only subjects with clinically suspicious thyroid nodules undergo thyroidectomy. Since histopathological evaluation is the gold 
standard, less than one-quarter of suspicious nodule that undergoes thyroidectomy are malignant. ${ }^{4,5}$

There is a lack of prevalence studies of thyroid cancer in Nepal. Nepal being a known iodinedeficient region, one can presume a high prevalence of thyroid malignancy in the Nepalese population. ${ }^{6}$ Lack of evidence makes real-world decision-making difficult. To inform clinicians and advocate for good policy-making regarding thyroid malignancy, we acknowledged the need for a prevalence study. This retrospective study was conducted to evaluate the prevalence and distribution of malignancy in thyroid nodule presenting with suspicious features in a tertiary center hospital of Nepal.

\section{METHODS}

A retrospective study was conducted at the Department of ENT- Head and Neck Surgery, Ganesh Man Singh Memorial Academy of ENT - Head and Neck Studies (GMSMA ENT HNS) from August 2017 to March 2020. A secondary data analysis from the study with clearance from Institutional Review Committee with Ref: 177/ (6-11) E2076/077) was used for this study. All the case records of subjects presented with clinically detected thyroid swelling at Ganesh Man Singh Memorial Academy of Otorhinolaryngology Head and Neck Studies Out Patient Department were retrieved and reviewed. Subjects ( $\mathrm{n}=183$ ) who underwent thyroidectomy or hemithyroidectomy with histopathological reports available were recruited in the study. To maintain patient confidentiality, we assigned each subject a serial number. Demographic profile was documented as age and gender. Pre-operative cytological findings and histopathological findings of subjects were entered into proforma.

Patients undergoing irradiation following FNAC were excluded from the study for the possibility of modifying the outcome of the study.

The findings were entered in Microsoft Office Excel (Microsoft Corporation, Redmond, US). SPSS Statistics for Windows, version 16.0 (SPSS Inc., Chicago, Ill., USA) was used for statistical analysis. The missing data were excluded from the statistical analysis. Descriptive statistics were used to find the mean, proportion, and percentage. An independent t-test was used to find the difference between the continuous variable, and we used Pearson's chisquared $(\chi 2)$ test to find an association between categorical variables. We defined a probability value (p-value) less than 0.05 to be statistically significant.

\section{RESULTS}

Altogether 183 subjects who underwent thyroidectomy at GMSMA - ENT HNS were recruited in the study. The mean age of subjects was $40.23 \pm 13.77$ years. Demographics of study participants are summarized in Table 1 and Table 2.

The majority of subjects fell into the age ranges from 41-50 years in total, and mainly comprised males. Whereas in females, most cases belonged to the age group of 21-30 years.

Most nodules that FNAC pre-operatively evaluated were diagnosed as papillary carcinoma followed by colloid goiter. (Figure 1)

Table 1: Distribution of study participants by gender $(n=183)$.

\begin{tabular}{|l|c|c|c|}
\hline \multicolumn{1}{|c|}{ Study participants } & Frequency (n) & Mean age \pm SD (years) & Age range \\
\hline Male & 31 & $42.25 \pm 13.56$ & $10-75$ \\
\hline Female & 152 & $39.81 \pm 14.81$ & $11-76$ \\
\hline Total & $\mathbf{1 8 3}$ & $\mathbf{4 0 . 2 3} \pm \mathbf{1 3 . 7 7}$ & $\mathbf{1 0 - 7 6}$ \\
\hline
\end{tabular}

We noted female preponderance in study subjects. Males were older than females. 
Table 2: Distribution of study participants by age group $(n=183)$.

\begin{tabular}{|c|c|c|c|c|}
\hline Age ( years) & Male & Female & Total (n) & Percentage (\%) \\
\hline$<20$ & 3 & 5 & 8 & 4.3 \\
\hline $21-30$ & 3 & 46 & 49 & 26.77 \\
\hline $31-40$ & 5 & 29 & 34 & 18.57 \\
\hline $41-50$ & 14 & 42 & 56 & 30.60 \\
\hline $51-60$ & 3 & 15 & 18 & 9.83 \\
\hline$>60$ & 3 & 15 & 18 & 9.83 \\
\hline Total & 31 & 152 & 183 & \\
\hline
\end{tabular}

Post-operative histopathological evaluation revealed that more than half $(n=98,53.55 \%)$ of the thyroid swellings that underwent thyroidectomy were benign.

The mean age of subjects with benign histopathological findings was $42.84 \pm 48$ years and with malignant histopathological findings was $37.63 \pm 13.90$ years. The difference in age was not statistically significant $(\mathrm{p}=0.928)$.
Papillary carcinoma was the most common histopathological finding in nodules that underwent surgical resection. Female dominance was maintained in nearly all histopathological findings. None of the male subjects were reported to have follicular carcinoma, multinodular goiter, medullary carcinoma, and Hashimoto thyroiditis.

The key findings that emerge from table 4 are

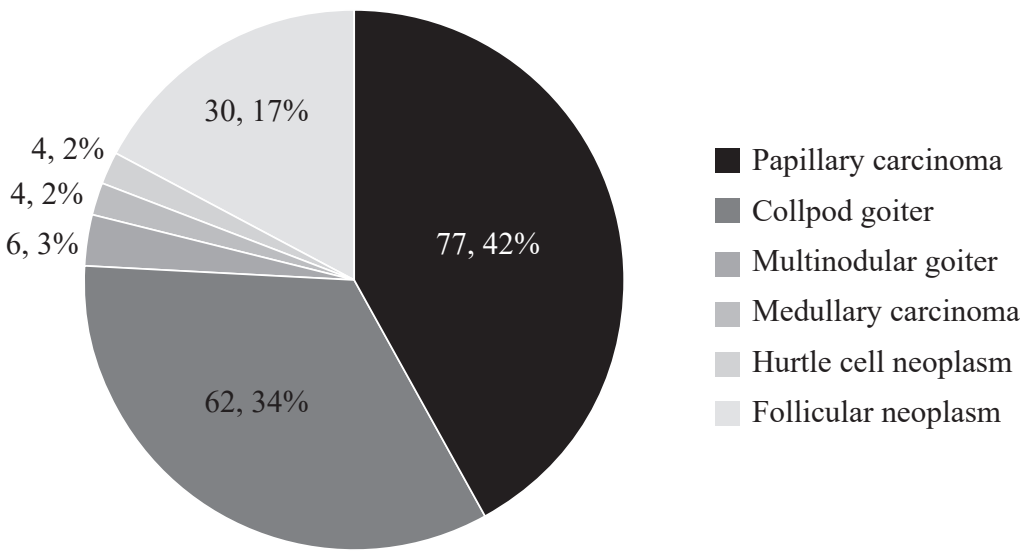

Figure1: Distribution of pre-operative fine needle aspiration cytology cases. $(n=183)$.

Table 3: Distribution of histopathological findings $(n=183)$.

\begin{tabular}{|l|c|c|c|}
\hline \multicolumn{1}{|c|}{ Histopathological finding } & Frequency (n) & Percentage (\%) & Female: Male \\
\hline Papillary carcinoma & 75 & 40.98 & $4.35: 1$ \\
\hline Colloid goiter & 57 & 31.14 & $3.75: 1$ \\
\hline Follicular adenoma & 21 & 13.72 & $9.5: 1$ \\
\hline Follicular carcinoma & 7 & 3.82 & $7: 0$ \\
\hline Multinodular goiter & 2 & 1.09 & $2: 0$ \\
\hline Medullary carcinoma & 4 & 2.18 & $4: 0$ \\
\hline Hurtle cell adenoma & 5 & 2.73 & $4: 1$ \\
\hline Hashimoto thyroiditis & 3 & 1.63 & $3: 0$ \\
\hline Cyst & 1 & 0.54 & $0: 1$ \\
\hline Free of tumor & 8 & 4.37 & $7: 1$ \\
\hline
\end{tabular}


Table 4: Histopathological distribution in subjects of different age groups.

\begin{tabular}{|l|c|c|c|c|c|c|}
\hline \multicolumn{1}{|c|}{ Age group (years) } & $<\mathbf{2 0}$ years & $\mathbf{2 1 - 3 0}$ years & $\mathbf{3 1 - 4 0}$ years & $\mathbf{4 1 - 5 0}$ years & $\mathbf{5 1 - 6 0}$ years & $>\mathbf{6 0}$ years \\
\hline Papillary carcinoma & 5 & 26 & 16 & 20 & 4 & 4 \\
\hline Follicular carcinoma & 1 & - & 1 & 2 & 1 & 2 \\
\hline Follicular adenoma & 1 & 9 & 6 & 1 & 3 & 1 \\
\hline Colloid goiter & - & 13 & 6 & 22 & 8 & 8 \\
\hline Hurtle cell adenoma & 1 & - & - & 3 & 1 & - \\
\hline Hashimoto thyroiditis & - & & 1 & 1 & 1 & - \\
\hline Mng & - & - & - & 2 & - & - \\
\hline Medullary carcinoma & - & - & 1 & 2 & - & 1 \\
\hline Thyroid cyst & - & - & - & 1 & - & - \\
\hline Free of tumor & - & 1 & 3 & 2 & - & 2 \\
\hline
\end{tabular}

papillary carcinoma encompassed to be the most frequent finding in all age groups below 50 years. Colloid goiter was the most common finding in the age group older than 50 years. Histopathological reports with the most variation were observed in the age group 41-50 years. We noted medullary carcinoma in age groups $31-40$ years and $41-50$ years only.

TThe prevalence of malignancy was higher in females (46.7\%) when compared with males $(45.2 \%)$. Nevertheless, we did not find any association between gender and malignancy in thyroid nodule $(\mathrm{p}=0.996)$ (Table 5).

The oldest mean age was seen in medullary carcinoma, whereas the youngest mean age was noted in follicular adenoma followed by papillary carcinoma. (Figure 2)

Table 5: Cross-tabulation of gender and histopathological finding in thyroid nodule $(n=183)$.

\begin{tabular}{|l|c|c|c|}
\multirow{2}{*}{ Gender } & \multicolumn{2}{|c|}{ Histopathological evaluation } & \multirow{2}{*}{ Total } \\
\cline { 2 - 4 } & Benign & Malignant & 152 \\
\hline Female & 81 & 71 & 31 \\
\hline Male & 17 & 14 & 183 \\
\hline
\end{tabular}

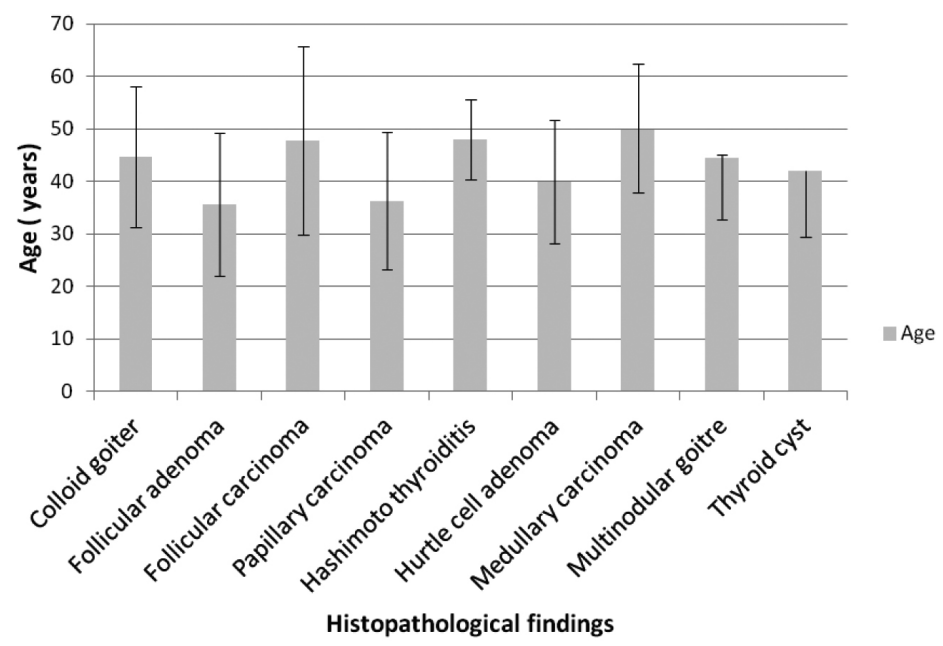

Figure 8: Mean age of subjects in different histopathological findings $(n=183)$. 


\section{DISCUSSION}

The prevalence of malignancy in thyroid swelling who underwent Hemi or total thyroidectomy in our hospital was $46.45 \%$. A similar study conducted by Hudise et al. ${ }^{7}$ found that $26.3 \%$ of tumors were malignant; our study found that number was higher. ${ }^{7}$ Earlier studies done in Nepal demonstrated the prevalence of malignancy in multinodular goiter as $13-13.6 \% .^{5,7}$ While analyzing malignancy in solitary thyroid nodule, the prevalence was reported to be $36.9 \%-39.7 \%{ }^{4,8}$ Since the current study was conducted at the tertiary center hospital of Nepal, and it explains a high prevalence of malignancy.

The incidence of thyroid carcinoma has been on the rise. Different diagnostic modalities like ultrasonography, fine needle aspiration cytology, and CT scan have significantly increased thyroid malignancy detection. Some authors attribute it to an increase in overdiagnosis rather than an actual increase in incidence in both high-income countries and urban areas of low-income countries. ${ }^{10} \mathrm{~A}$ recent study demonstrated a low mutation frequency of thyroid carcinoma when compared with another carcinoma. Being a highly active organ, it is also frequently exposed to oxidative stress. ${ }^{9,10}$

The mean age of patients recruited in this study was similar to Pradhan et al. ${ }^{9}$ Most subjects recruited in the current study presenting with thyroid nodules were in the fifth decade, which did not corroborate previous studies. ${ }^{5,7,11}$ Only patients with multinodular goiter were included in similar studies conducted in Nepal. ${ }^{5,7}$ Majority of females in the current study fell into the age group 21-30 years and did not follow the finding of Shrestha et al. ${ }^{4}$ We observed similar discordance in the distribution of males according to age group. There was notable female predilection in this study which was seemingly following existing literature. ${ }^{7,11,12}$

In contrast to earlier findings of colloid goiter as the most common pre-operative FNAC finding, we did not replicate similar observations. Current study found out that majority of lesion were preoperatively diagnosed as papillary carcinoma (42\%), however, this doesn't imply that majority of lesion pre-operatively were malignant in nature. Around $34 \%$ lesions were colloid and $17 \%$ were follicular neoplasm. Also, pre-operatively follicular neoplasm cannot be differentiated as benign or malignant. Further during literature review, we observed that most lesion post-operatively was benign as in Shrestha et al. ${ }^{4}$ and Pradhan et al. ${ }^{9}$ Since we only undergo thyroidectomy for clinically suspicious nodules, our institute's USG-guided FNAC technology and faculty's expertise as a tertiary care center would have helped in making better decisions on which lesions to remove. This could have resulted in a higher occurrence of malignant findings in the thyroid that underwent thyroidectomy in the present study than in older studies.

The significant difference in the mean age of benign and malignant, and older means benign age was in contradiction to Ibrahim et al. ${ }^{13}$ The older mean age of the benign group in the current study corresponded to the predictive model study. ${ }^{14}$ Supportive to findings of our study, Kwong et $\mathrm{al}^{15}$ pointed out that the likelihood of malignancy in thyroid nodule decreased with an increase in age and considered it a clinical paradox.

Gender disparity observed in our study is substantiated by Rahbari et al. ${ }^{16}$ The author asserted that differentiated thyroid cancer is more common in females, and there is equal gender distribution in medullary cancer. We, however, partially agree with the study as we reported female predilection in all types of thyroid carcinoma. Hoelting et al. demonstrated that estrogen receptor blocker " Tamoxifen" could successfully inhibit the growth of follicular carcinoma, so female predilection in follicular carcinoma could be due to estrogen. ${ }^{17} \mathrm{We}$, however, did not find any significant association between gender and malignancy. Tai et al. demonstrated male gender as an independent risk factor for thyroid malignancy in a solitary thyroid 
nodule. ${ }^{21}$

Papillary carcinoma surpassed the most common finding in our study participants, which was maintained across all age groups below 50 years. Uyar et al. reported papillary carcinoma as the most common histopathological finding in subjects presenting with solitary thyroid nodule at the biggest oncology hospital in Turkey. ${ }^{8}$ But our finding did not substantiate with a similar study where colloid goiter was the most common finding in a thyroid nodule. ${ }^{4,7,12,18}$

Above 50 years, however, colloid goiter was the most common histopathological finding. Papillary carcinoma was the most common malignant finding across earlier studies. ${ }^{5,7,12}$

The mean age of subjects presenting with papillary carcinoma was relatively younger than follicular carcinoma and medullary carcinoma.

Papillary carcinoma was the most common finding in both genders, followed by colloid goiter. Peak prevalence of papillary carcinoma was observed in the third decade in females. Kilfoy et al., however, noted an increase in the incidence of papillary thyroid cancer in the fifth decade in the female gender. ${ }^{19}$
Since this is a hospital-based study, our findings cannot be extrapolated to the general population as patients recruited in the study had suspicious thyroid nodules. Being a retrospective study, we relied totally on record keeping.

Thus, we would like to suggest a community-based longitudinal study to delimitate the drawbacks of a hospital-based cross-sectional study. Future studies should be focused on strategically examining attributes related to human error of surgically operating more than half of benign thyroid nodules.

\section{CONCLUSIONS}

The majority of thyroid nodules that underwent thyroidectomy had underlying papillary carcinoma, and we recommend that any thyroid nodule presented in the hospital be given a complete clinical, biochemical, radiological, and pathological evaluation to rule out malignancy.

\section{Conflict of Interest: None}

\section{REFERENCES}

1. Brown RL, de Souza JA, Cohen EE. Thyroid Cancer: Burden of Illness and Management of Disease. J Cancer. 2011 Apr 4;2:193-9.

2. Gharib H, Papini E, Valcavi R, Baskin HJ, Crescenzi A, Dottorini ME, Duick DS, Guglielmi R, Hamilton CR Jr, Zeiger MA, Zini M; AACE/AME Task Force on Thyroid Nodules. American Association of Clinical Endocrinologists and Associazione Medici Endocrinologi medical guidelines for clinical practice for the diagnosis and management of thyroid nodules. Endocr Pract. 2006 Jan-Feb;12(1):63-102. doi: 10.4158/EP.12.1.63. Erratum in: Endocr Pract. 2008 Sep;14(6):802-3. multiple author names added. PMID: 16596732

3. Choi WJ, Kim J. Dietary factors and the risk of thyroid cancer: a review. Clin Nutr Res. 2014 Jul;3(2):75-88.

4. Jena A, Patnayak R, Prakash J, Sachan A, Suresh V, Lakshmi AY. Malignancy in solitary thyroid nodule: A clinicoradiopathological evaluation. Indian J Endocrinol Metab. 2015 Jul-Aug;19(4):498-503. doi: 10.4103/2230-8210.159056. PMID: 26180765; PMCID: PMC4481656.

5. Shrestha D, Shrestha S. The Incidence of Thyroid Carcinoma in Multinodular Goiter: A Retrospective Study. J Coll Med Sci-Nepal. 2014;10(4):18-21.

6. Bhandari S, Banjara MR. Micronutrients Deficiency, a Hidden Hunger in Nepal: Prevalence, Causes, Consequences, and Solutions. Int Sch Res Not. 2015 Jan 15;2015:e276469.

7. Pradhan G, Shrestha R, Shrestha S, Neupane J, Bhattachan J. The Incidence of Thyroid Carcinoma in Multinodular Goiter : a prospective study. Nepal Med Coll J. 2011;13(3):169-71.

8. Uyar O, Cetin B, Aksel B, Dogan L, Beksac K, Akgul GG, et al. Malignancy in Solitary Thyroid Nodules: Evaluation of Risk Factors. Oncol Res Treat 2017;40(6):360-3.

9. Kim WB. A Closer Look at Papillary Thyroid Carcinoma. Endocrinol Metab. 2015 Mar;30(1):1-6

10. Lawrence MS, Stojanov P, Polak P, Kryukov GV, Cibulskis K, Sivachenko A, et al. Mutational Heterogeneity in Cancer and The Search for New Cancer-Associated Genes. Nature. 2013 Jul 11;499(7457):214-8. 
11. Hudise JY, Alshehri KA, Alqarni SN, Assiri Y, Asiri A, Aljobran B, et al. Prevalence and Pattern of Thyroid Malignancy in Thyroid Nodule in Aseer Central Hospital in KSA. Int J Otorhinolaryngol Head Neck Surg. 2017 Oct;3(4):908-12.

12. Keh SM, El-Shunnar SK, Palmer T, Ahsan SF. Incidence of malignancy in solitary thyroid nodules. J Laryngol Otol. 2015 Jul;129(7):677-81.

13. Ibrahim MMES, Omar W, Elhofy A. Prospective Study Evaluating Malignancy in Solitary Thyroid Nodule. Egypt J Surg. 2019;38(3):411-7.

14. Girardi FM, Silva LM da, Flores CD, Girardi FM, Silva LM da, Flores CD. A Predictive Model to Distinguish Malignant and Benign Thyroid Nodules Based on Age, Gender and Ultrasonographic Features. Braz J Otorhinolaryngol. 2019 Feb;85(1):24-31.

15. Kwong N, Medici M, Angell TE, Liu X, Marqusee E, Cibas ES, et al. The Influence of Patient Age on Thyroid Nodule Formation, Multinodularity, and Thyroid Cancer Risk. J Clin Endocrinol Metab. 2015 Dec;100(12):4434 40

16. Rahbari R, Zhang L, Kebebew E. Thyroid Cancer Gender Disparity. Future Oncol Lond Engl. 2010 Nov;6(11):1771-9.

17. Hoelting T, Duh QY, Clark OH, Herfarth C. Tamoxifen Antagonizes Proliferation and Invasion of Estrogen Receptor-Negative Metastatic Follicular Thyroid Cancer Cells via Protein Kinase C. Cancer Lett. 1996 Feb 27;100(1-2):89-93.

18. Sengupta A, Pal R, Kar S, Zaman FA, Sengupta S, Pal S. Fine Needle Aspiration Cytology as the Primary Diagnostic Tool in Thyroid Enlargement. J Nat Sci Biol Med. 2011;2(1):113-8.

19. Kilfoy BA, Devesa SS, Ward MH, Zhang Y, Rosenberg PS, Holford TR, et al. Gender is an Age-Specific Effect Modifier for Papillary Cancers of the Thyroid Gland. Cancer Epidemiol Biomark Prev Publ Am Assoc Cancer Res Cosponsored Am Soc Prev Oncol. 2009 Apr;18(4):1092-100. 